\title{
A POSSIBILIDADE DE AÇÃO DO TRIBUNAL PENAL INTERNACIONAL EM UGANDA E NA REPÚBLICA CENTRO AFRICANA: UMA JUSTIÇA QUE AMEAÇA A PAZ?
}

Maurílio Braz Santana Jr. ${ }^{1}$

\section{RESUMO}

O artigo é uma abordagem sobre a possibilidade de ação do Tribunal Penal Internacional em Uganda e na República Centro Africana.

\section{INTRODUÇÃO}

O presente artigo tem por objetivo verificar a possibilidade de atuação do Tribunal Penal Internacional (TPI) ${ }^{2}$, para analisar e julgar abusos contra os direitos humanos praticados em Uganda e na República Centro Africana. Tais abusos, cometidos tanto por grupos rebeldes quanto pelo poder instituído, são suspeitos de serem crimes que podem ser julgados pelo TPI, segundo o disposto no Estatuto de Roma ${ }^{3}$.

Ao se falar em 'possibilidade' de atuação do Tribunal, busca-se averiguar a legitimidade, competência, tipicidade e condições práticas para a ação da Corte. Esse artigo objetiva constatar se os tipos, casos e situações ocorridas nos países se enquadram na finalidade para a qual foi criado o TPI. Neste trabalho, faz-se também uma análise da legislação dos países e a recepção da legislação internacional em seus ordenamentos.

\footnotetext{
${ }^{1} \mathrm{O}$ autor é Acadêmico de Direito e membro do Núcleo de Estudos de Direito Internacional da Universidade Federal do Paraná

${ }^{2}$ O Tribunal Penal Internacional, com sede na Haia, Países Baixos, é a primeira Corte Criminal Internacional permanente, baseada em tratado, estabelecida para promover a aplicação da lei e garantir que os mais graves crimes internacionais sejam punidos. O Tribunal começou suas atividades em 1 de julho de 2002 e tem jurisdição para julgar os crimes cometidos a partir dessa data.

${ }^{3}$ O Estatuto de Roma estabelece o fundamento legal para o funcionamento e a jurisdição do Tribunal Penal Internacional. O conteúdo do Estatuto foi redigido e publicado em 17 de julho de 1998, durante a "Conferência Diplomática das Nações Unidas para o Estabelecimento de uma Corte Criminal Internacional", que contou com a participação de 120 Estados e passou a vigorar em 01 de julho de 2002 após a ratificação de suas disposições por 60 Estados-parte. Até hoje, 99 países já ratificaram o Estatuto de Roma.
}

Revista Brasileira de Direito Internacional, Curitiba, v.1, n.1, jan./jun.2005 
Dentro do viés prático do presente artigo, discute-se a posição de certos setores da sociedade dos países em conflito, que afirmam que a ação do TPI, através da investigação, julgamento e punição dos envolvidos, possa ser uma ameaça à paz da região. Por mais estranha e contraditória que essa afirmação possa parecer a primeira vista, argurmenta-se que a punição dos criminosos possa reacender os ânimos dos grupos rebeldes, que buscarão vingar-se ou impedir uma negociação para estabelecer a paz.

\subsection{UGANDA - HISTÓRICO DO CONFLITO}

O conflito em Uganda tem ocorrido nos últimos dezoito anos, durante os quais a população civil do norte de Uganda (ver mapa da página 3) tem sofrido constantes ataques. A tensão iniciou-se logo após a chegada do Presidente Yoweri Museveni ao poder, em 1986, que derrotou o presidente Tito Okello.

Okello representava o povo Acholi, uma das etnias do norte de Uganda. Um grupo rebelde chamado Lord's Resistence Army - LRA (isso mesmo, Exército de Resistência de Deus) foi formado a partir do ressentimento de parte do povo Acholi, devido a sua perda de influência com a queda do presidente. Resquícios de movimentos que eram originários do antigo Ugandan People Democratic Army - UPDA, que também atuou contra o governo de Museveni entre 1986 e 1988, engrossaram as fileiras do grupo.

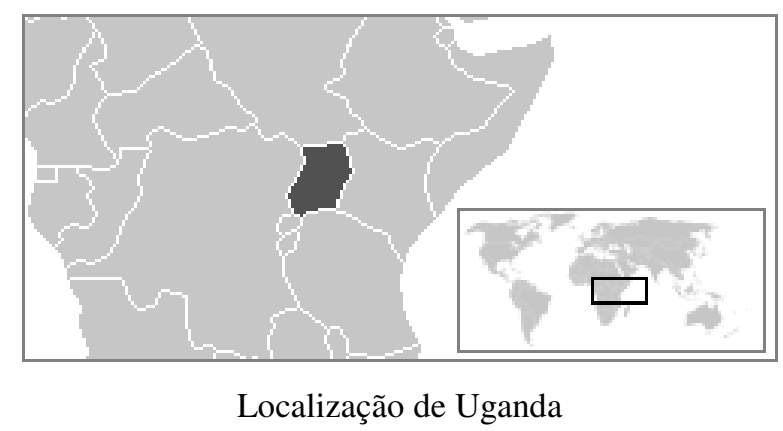

(Fonte: http://upload.wikimedia.org/wikipedia/commons/e/ef/LocationUganda.png)

Durante o período em que Uganda esteve sob o jugo da coroa da Inglaterra, os britânicos encorajaram o desenvolvimeto social e político do sul

Revista Brasileira de Direito Internacional, Curitiba, v.1, n.1, jan./jun.2005 
do país. Em contraste, os Acholi e outros grupos étnicos do norte ficaram economicamente atrasados em relação ao sul, sendo que boa parte permaneceu em situação de miséria extrema ou submeteu-se a trabalho escravo nas lavouras e periferias das cidades. Depois da independência de Uganda, os Acholi passaram a ser maioria no exército, sua influência cresceu e chegaram a tomar o poder com o General Tito Okello, que foi deposto pelo atual presidente Museveni.

O LRA é engajado numa rebelião armada contra o governo de Uganda e alimenta um dos conflitos mais duradouros da África. É liderado por Joseph Kony, um acholi de Gulu, que proclama a si mesmo como um espírito de medium e aparentemente deseja estabelecer um Estado teocrático baseado na sua própria interpretação do milenarismo bíblico. O grupo de Kony força seu próprio povo Acholi a se juntar a seu exército através das práticas descritas a seguir.

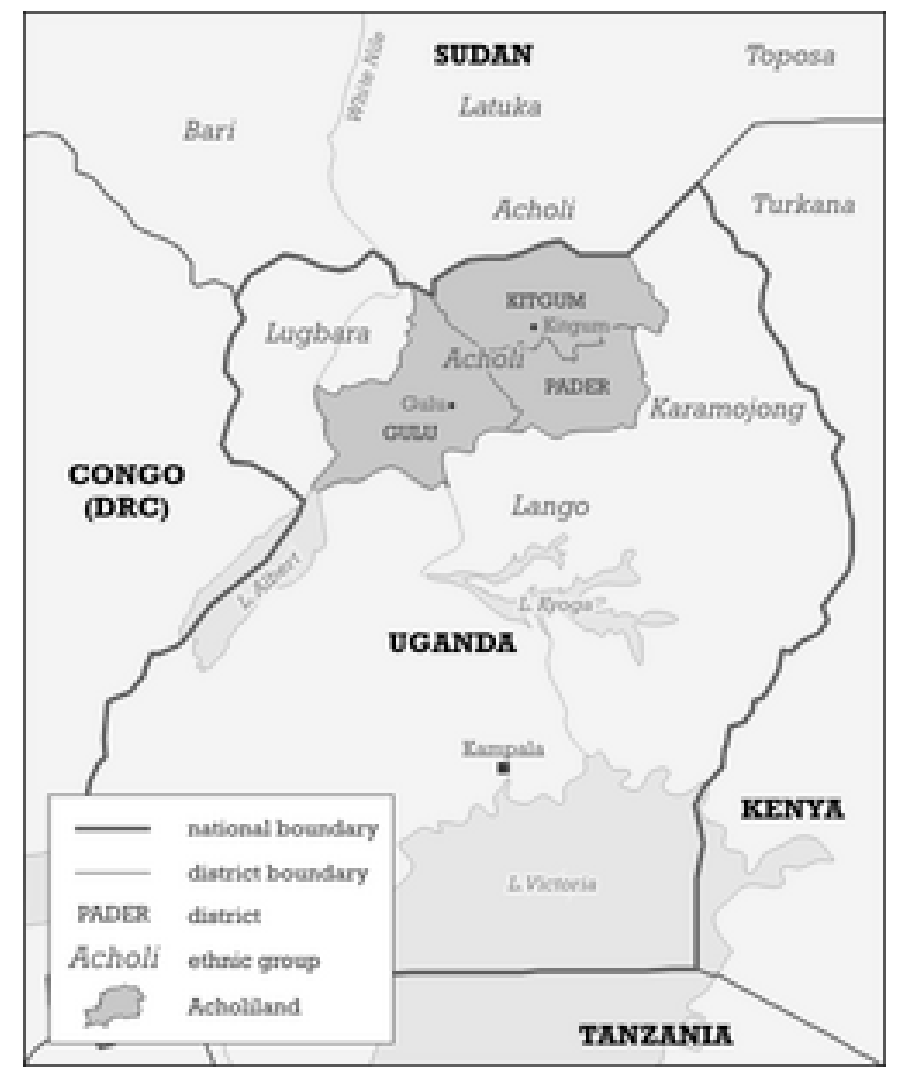

Região habitada pelo povo Acholi, que é vítima da ação do LRA

(Fonte: http://upload.wikimedia.org/wikipedia/en/6/6a/Acholiland\%2C_Uganda.png)

Os ataques aos civis têm pelo menos três objetivos. Primeiro, desmentir o governo perante a comunidade internacional, que afirma que as Revista Brasileira de Direito Internacional, Curitiba, v.1, n.1, jan./jun.2005 
atividades do LRA estão diminuindo. Segundo, obter provisões saqueando os vilarejos. Terceiro e mais bizarro, mostrar a população que o governo é incapaz ou negligente ao prover proteção aos cidadãos e assim encorajar a população a apoiá-los.

A partir 1994, o grupo teve auxílio do governo do Sudão, que abrigava os líderes do movimento e dava suporte logístico. Além disso, o governo sudanês fornecia armas, munição e minas terrestres aos rebeldes. Em contrapartida, o LRA participava de ações conjuntas com o exército do Sudão. Essa atitude do Sudão foi uma retaliação ao apoio dado pelo governo de Uganda ao Sudan People Liberation Army (SPLA), do sul do país, durante a guerra civil sudanesa. A evolução dos hostilidades entre os países causou a ruptura diplomática entre eles. Os países voltaram a ter relações diplomáticas apenas em 2001.

De acordo com diferentes relatórios que chegaram a Promotoria do Tribunal Penal Internacional, o conflito resultou em sérios abusos aos direitos humanos contra a população civil da região, incluindo execuções sumárias, tortura e mutilação, recrutamento de crianças como soldados, abuso sexual de crianças, seqüestro, mudanças de residência forçadas, saques e destruição de propriedades.

A base de combatentes do LRA é constituída principalmente por pessoas raptadas entre o povo Acholi, especialmente crianças, a maioria com idades entre 11 e 15 anos, além de crianças menores. De acordo com relatórios que foram entregues a Promotoria do TPI por organizações não governamentais, $85 \%$ das forças são constituídas por crianças, usadas como soldados, carregadores, trabalhadores e escravas sexuais, no caso da meninas. Como parte da iniciação no movimento rebelde, as crianças seqüestradas são forçadas a cometer atos desumanos, incluindo rituais de mutilação e morte. Mais de 20.000 crianças raptadas são usadas para carregar fardos pesados por longas distâncias, saquear e incendiar casas, espancar e matar civis e outros raptados, além de seqüestrar outras crianças.

Durante os últimos anos, mais de 12.000 pessoas foram mortas em conseqüência do conflito e estima-se que cerca de 2 milhões foram obrigadas a 
deixar suas casas, vivendo em campos de refugiados espalhados pelo interior do país ou nas ruas das cidades maiores. Apesar de todas estas atrocidades, apenas em abril de 2004, o Conselho de Segurança da ONU condenou formalmente o conflito. Um grupo de profissionais em direitos humanos elegeram o conflito em Uganda como o segundo pior conflito esquecido pelo mundo desenvolvido.

Os mesmos relatórios mencionam que na tentativa de evitar sua captura, milhares de crianças tornaram-se "moradores da noite", andando vários quilômetros para se reagruparem em centros mantidos por organizações não-governamentais, nas ruas, nas proximidades de lojas e igrejas e em fábricas, voltando aos seus vilarejos ao amanhecer.

Depois de raptadas, muitas moças são usadas como criadas dos comandantes, enfrentando duros trabalhos domésticos de longas horas e freqüentes espacamentos. Outras mulheres cativas são forçadas a tornarem-se "esposas" de soldados mais velhos ou são dadas como recompensa sexual a soldados-meninos obedientes, sendo submetidas a estupros, gravidez indesejada e ao risco de doenças sexualmente transmissíveis.

Um relatório do próprio governo de Uganda aponta que os ataques pelo LRA ocorridos durante os anos 90 forçaram que cerca de $75 \%$ do povo Acholi deixasse suas casas nos distritos de Gulu e Kigum/Pader, no norte do país. No ano de 2003, a intensificação das atividades do LRA levou a dobrar a população dos campos de refugiados de 400.000 a 800.000 pessoas. Esse reacendimento dos ataques do grupo foi um contra-ataque a ofensiva do governo de Uganda, que atacou a bases o LRA no sul do Sudão.

Isso também tem sido relatado como parte do modo de violento que aterroriza a população, incluindo tortura e mutilação do corpo, amputação dos mãos, orelhas ou lábios dos habitantes dos vilarejos que são suspeitos de simpatia com o governo. Além disso, durante o curso do conflito, o LRA queimou pelo menos 2.000 casas e 1.600 armazens, saqueou 1.400 casas, 116 vilarejos e 307 lojas.

Atualmente, o governo de Uganda tem reforçado suas tropas na região e também formado milícias locais, fornecendo armas a população civil para a 
sua própria defesa. Esse procedimento tem preocupado as autoridades internacionais de que o conflito possa se agravar ainda mais.

Apesar dos horrores do conflito, alguns avanços nos últimos 6 meses têm dado aos observadores internacionais duas razões para otimismo. Primeiro, o Lord's Resistance Army está enfraquecido pela ação mais incisiva do exército de Uganda, pressionado pela investigação do Tribunal Penal Internacional e pela diminuição do apoio dado pelo governo sudanês às tropas do LRA. Segundo, a ação diplomática que está sendo empreendida por Betty Bigombe, ex-ministra de Estado de Uganda, abriu contato com os líderes do grupo rebelde, dando a eles uma opção de saída do conflito.

Os crimes alegados que estão sendo cometidos na região (recrutamento de crianças como soldados, assassinatos cruéis, estupro, escravidão sexual, gravidez forçada e mudança forçada de civis) constituem crimes contra a humanidade de acordo com o Estatuto de Roma.

\subsection{REPÚBLICA CENTRO AFRICANA - HISTÓRICO DO CONFLITO}

Europeus chegaram à região em 1885, incluindo franceses e alemães. Em 1894, a França tomou posse como colônia agrícola. A República Centro Africana tornou-se independente em 13 de agosto de 1960.

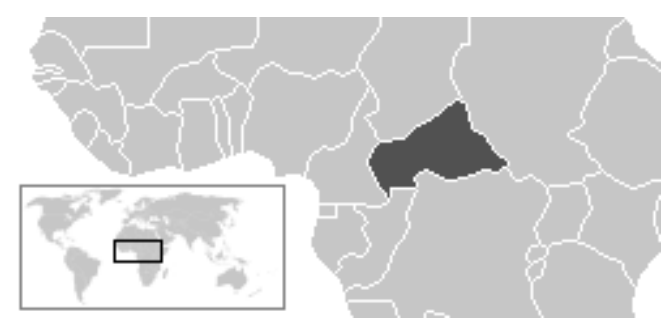

Localização da República Centro Africana

(Fonte: http://en.wikipedia.org/wiki/Central_African_Republic\#Politics)

A história do país é marcada pela instabilidade política. Inaugurou sua independência com o período ditatorial do presidente David Dacko. Este foi deposto em 1966 por seu sobrinho Jean-Bedél-Bockassa, que manteve o modo de ditadura militar. Em 1977, Bockassa se auto-proclamou imperador e foi coroado numa cara cerimônia. Suas violações aos direitos humanos, que incluíam o canibalismo e a alimentação de crocodilos com crianças, além de 
contrariar interesses franceses no país, fizeram com que a França apoiasse a retomada do poder pelo Pres. Dacko, em 1979. Em seguida, Dacko foi deposto por Andre Kolingba. Sucederam-se a ele através da tomada forçada do poder o Pres. Angé-Felix Patassé, que governou entre 1993 a 2003. Recentemente, o poder foi tomado por um golpe militar de François Bozizé, em março de 2003.

O novo governo criou o Ministério da Justiça, Direitos Humanos e Bom Governo e uma Comissão Nacional de Direitos Humanos. Entretanto, membros das forças de segurança do país impediram o trabalho da comissão.

O conflito tem ainda a influência do Movimento pela Libertação do Congo - MLC, um grupo político armado da vizinha República Democrática do Congo e de tropas do governo da Líbia que apoiaram o presidente Patassé. As tropas do Chade apoiaram o atual presidente Bozizé.

Durante os anos de 2002 e 2003, os combatentes sistematicamente violentaram milhares de mulheres. Muitas mulheres foram violentadas por tropas do MLC, incluindo crianças-soldado e outras pelas forças leais ao Pres. Bozizé. Algumas vítimas morreram ao tentar evitar o estupro e outras, em conseqüência das agressõas sofridas. Outras vítimas que sobreviveram foram infectadas por doenças sexualmente transmissíveis e acabaram abandonadas por seus cônjuges, além dos casos de gravidez indesejada. A mutilação de órgão genitais femininos é amplamente praticada. Na maioria dos casos nenhuma atitude das autoridades foi tomada contra os membros do MLC durante o governo do presidente Patassé nem contra as tropas do presidente François Bozizé após a sua assunção ao poder em março de 2003.

Tanto as forças do governo como da oposição armada têm executado sumariamente milhares de civis sob acusação de apoiarem seus oponentes. Relatos de tortura de ambas as partes chegam todos os dias às autoridades internacionais. Devido a essas práticas, milhares de pessoas estão internamente sem lugar para ficar, em acampamentos provisórios ou campos montados por organizações não-governamentais. Milhares de refugiados foram para outros países.

Em especial na capital Bangui, o governo faz vistas grossas à ação de seus soldados em torturas e execuções sumárias, além da ação de grupos de 
extermínio. Saques e incêndios aos vilarejos são constantes pelas forças rebeldes. Depois da tomada do poder pelo Pres. Bozizé, as tropas do MLC foram expulsas para o Congo.

Embora o Código Penal do país proíba a tortuta, entretanto a polícia continua a torturar e a matar suspeitos.

Nenhuma ação ação foi tomada contra as tropas oficiais, rebeldes e grupos estrangeiros que cometeram abusos contra a população durante 0 conflito.

Revista Brasileira de Direito Internacional, Curitiba, v.1, n.1, jan./jun.2005 


\section{ATUAÇÃO DA ONU E DO TRIBUNAL PENAL INTERNACIONAL: AÇÕES JÁ TOMADAS E SUA CONFORMIDADE COM O DISPOSTO NO ESTATUTO DE ROMA}

Em novembro de 2003, durante uma visita a Uganda, Jan Egeland, Secretário da ONU para assuntos humanitários e coordenador de socorro de emergência disse: "Eu não posso encontrar em nenhuma outra parte do mundo que esteja acontecendo uma emergência tão grave quanto em Uganda e que

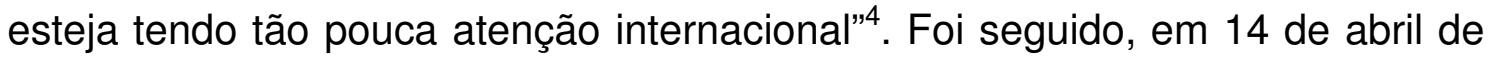
2004, pela condenação do Conselho de Segurança da ONU pelas atrocidades cometidas pelo LRA.

Em dezembro de 2003, o Presidente de Uganda, Yoweri Museveni, solicitou a ajuda do Tribunal Penal Internacional, usando a prerrogativa que the reserva o artigo 14 do Estatuto de Roma, fazendo uma denúncia por haver indícios de ter ocorrido a prática de crimes de competência do Tribunal, que deverá julgar se o LRA é culpado de crimes contra a humanidade. O promotor do TPI, Luis Moreno-Ocampo, abriu formalmente uma investigação, em janeiro de 2004, para apurar os abusos contra os direitos humanos ocorridos em Uganda.

Entretanto, essa ação do presidente desagradou a muitos grupos internos de Uganda e soube-se que o governo estava tentando voltar atrás em sua denúncia ao TPI. O Tribunal, por sua vez, reforçou sua intenção de continuar investigando o caso.

Em fevereiro de 2005, durante sua visita ao Quênia, o Chefe de Relações Públicas do TPI, Chistian Palme, anunciou que mandados de detenção preventivos serão determinadas para os líderes do LRA, sob a acusação de crimes contra a humanidade. Caso isso ocorra, serão as primeiras prisões decretadas pelo TPI desde que foi estabelecido em julho de 2002. Esses mandados de prisão encontram fundamento legal no artigo 58 do Estatuto de Roma, que determina que "a todo momento após a abertura do inquérito, o Juízo de Instrução poderá, a pedido do procurador, emitir um

Revista Brasileira de Direito Internacional, Curitiba, v.1, n.1, jan./jun.2005 
mandado de detenção ..." para garantir o comparecimento da pessoa ao Tribunal ou impedir que a pessoa continue a cometer o crime, que deve ser o fudamento de tal ato.

Segundo Palme, o promotor-chefe do TPI, Luis Moreno Ocampo, disse que iniciaria o julgamento dos primeiros crimes em julho de $2005 .^{5}$

Já a denúncia dos atos cometidos na República Centro Africana foi feita por um membro do governo daquele país ao Escritório da Promotoria do Tribunal Penal Internacional em 21 de dezembro de 2004. O caso encontra-se em fase inicial de investigação na Corte.

\footnotetext{
${ }^{4}$ BBC NEWS. Uganda conflict 'worse than Iraq' (BBC News, 10-11-2003) Disponível em HTTP http://news.bbc.co.uk/2/hi/africa/3256929.stm Acesso às 00:20h do dia 07.set.05

${ }^{5}$ MONUC NEWS. UN criminal court to target Uganda rebels, DR Congo militia AFP. (Monuc News, 08-02-2005) Disponível em HTTP http://www.monuc.org/news.aspx?newsID=5480 Acesso às 06:25h do dia 08.set.05
}

Revista Brasileira de Direito Internacional, Curitiba, v.1, n.1, jan./jun.2005 


\section{POSSIBILIDADE LEGAL E FÁTICA DE ATUAÇÃO DO TRIBUNAL} PENAL INTERNACIONAL: LEGISLAÇÃO LOCAL E POSSÍVEIS AÇÕES A SEREM TOMADAS

O papel do TPI em Uganda é delicado e, de certa forma, controverso. Isso porque punir os culpados pelos crimes praticados pode prolongar o conflito e retardar a paz. Caso Joseph Kony seja indiciado e trazido à justiça, a população local receia que o grupo rebelde sinta-se pressionado e menos disposto a encerrar a guerra. Isso poderia atrapalhar o trabalho diplomático que está sendo realizado por Betty Bigombe 6 . "Essa ação [de expedir mandados de prisão] nesse momento irá atrapalhar o acordo de paz que está sendo negociado entre as partes. Interromperei meu trabalho diplomático caso os mandados de prisão sejam expedidos pelo Tribunal Penal Internacional ", disse a estadista.

Essa declaração da ex-ministra de Uganda chama a atenção e por isso dá título a este artigo: pode a justiça atrapalhar a paz? Essa afirmação de certa maneira é contraditória à "função específica do Direito Penal que é a tutela juridica"7 , ou seja, proteger os bens jurídicos mais importantes e não colocá-los em risco. Além disso, o meio de ação de que se vale o Direito Penal, que é a pena, "tem finalidade preventiva, no sentido de evitar a prática de novas infrações". A prevenção tem caráter geral quando se observa que o "fim intimidativo da pena dirige-se a todos os destinatários da norma penal, visando a impedir que os membros da sociedade pratiquem crimes"9. Tem ainda caráter especial, pois a "pena visa o autor do delito, retirando-o do meio social, impedindo-o de delinqüir e procurando corrigí-lo."10

Seria ingênuo pensar que a declaração da ex-ministra tenha o objetivo de negar a eficácia da pena como repressora da ação criminosa. Na realidade, é possível entender que a intenção de Bigombe foi chamar a atenção da

\footnotetext{
${ }^{6}$ Betty Oyella Bigombe é ex-ministra de Uganda e consultora do Banco Mundial. De origem da etnia acholli, tem mestrado em Harvard e na Escola de Governo Kenedy. È tida como a única voz que pode ser ouvida por ambos lados do conflito.

7 JESUS, Damásio de. Direito Penal - Parte Geral. São Paulo: Saraiva, 1998.

${ }^{8}$ Idem ao 7.

${ }^{9}$ Idem ao 7
}

Revista Brasileira de Direito Internacional, Curitiba, v.1, n.1, jan./jun.2005 
comunidade internacional para a completa ausência do Estado na proteção do indivíduo e ressaltar que não adianta simplesmente capturar e julgar os líderes do LRA. Caso a situação social e fática dos cidadãos permaneça a mesma outros Konys surgirão. Não se precisa ir longe para sentir a angústia da estadista ugandense. Na prática policial dos países sabe-se que, a cada líder do crime organizado morto, outros surgem É necessária a atuação de outras forças do Poder Público. O mesmo se aplica ao país africano. O julgamento e a prisão dos líderes do LRA por si só não trarão a paz a Uganda.

Outro fato relevante é que o requerimento feito ao TPI pelo governo de Uganda foi exclusivamente para coletar evidências de crimes de guerra cometidos pelo LRA em geral e por seu líder Joseph Kony em particular. A solicitação por ajuda da justiça internacional deixa de fora os crimes praticados pelo Ugandan People Democratic Force - UPDF, a força oficial de Uganda. "Nossa posição é que se os investigadores do TPI vierem a levantar qualquer alegação contra integrantes do exército ou governo de Uganda, estes deverão ser julgados pelo governo"11, disse Shaban Bantarisa, porta-voz do exército. Entretanto, essa ressalva feita pelo governo de Uganda contraria claramente 0 Estatuto de Roma, que em seu artigo 27 estabelece que "será aplicável de forma igual a todas as pessoas sem distinção alguma baseada na qualidade oficial (...) [essa condição] em caso algum eximirá a pessoa em causa de responsabilidade criminal nos termos do presente Estatuto, nem constituirá de per se motivo de redução de pena." Os chefes militares e superiores hierárquicos têm ainda responsabilidade sobre os atos praticados por seus subordinados, nos termos do Artigo 28 do Estatuto.

Uganda assinou o Estatuto de Roma em 17 de Março de 1999 e o ratificou em 14 de junho de 2002, tornando-se o seu 68ํㅡㄹ Estado-parte. Sendo assim, submete-se aos seus poderes e funções, nos termos do Estatuto de Roma, artigo 12, parágrafo $1^{\circ}$.

\footnotetext{
${ }^{10}$ Idem ao 6

${ }^{11}$ ALL AFRICA. No Fundamental Change for Northern Uganda (AllAfrica.com, 09-09-2005) Disponível em HTTP http://allafrica.com/stories/200509090638.html Acesso às 23:45h do dia 15.set.05
}

Revista Brasileira de Direito Internacional, Curitiba, v.1, n.1, jan./jun.2005 
A constituição de Uganda foi promulgada em 22 de setembro de 1995. Já no seu preâmbulo o texto constitucional define que a política externa do país será pautada na observância das leis internacionais e das obrigações dos tratados. Também na parte preambular está contida declaração de que o Estado participará ativamente de organizações internacionais que busquem a paz e o bem estar da humanidade. O artigo 23 da Constituição Federal, em seu inciso 1 letra $A$, determina que "nenhuma pessoa será privada da liberdade exceto por cumprimento de sentença ou ordem de tribunal estabelecido em Uganda ou por tribunal internacional quando a respeito de uma ofensa criminal." Ora, observa-se que o próprio texto da constituição ugandense recepciona a jurisdição do Tribunal Internacional.

A República Centro Africana também é Estado-parte do Tribunal Penal Inernacional. O país assinou o Estauto de Roma em 7 de dezembro de 1999 e o ratificou em 3 de outubro de 2001, tornando-se o 41ํㅡㄹ Estado-parte. Sendo assim, submete-se a todos os direitos e deveres contidos no Estatuto de Roma.

Revista Brasileira de Direito Internacional, Curitiba, v.1, n.1, jan./jun.2005 


\title{
4 O ESTATUTO DE ROMA E OS ATOS PRATICADOS NOS PAÍSES: PONTOS DE CONVERGÊNCIA E DIVERGÊNCIA
}

\author{
Do preâmbulo \\ (...) “Tendo presente que, no decurso do século XX, milhões de crianças, \\ homens e mulheres têm sido vítimas de atrocidades inimagináveis que \\ chocam profundamente a consciência da humanidade, \\ Reconhecendo que crimes de uma tal gravidade constituem uma ameaça a \\ paz, à segurança e ao bem-estar da humanidade, \\ Afirmando que os crimes de maior gravidade, que afetam a comunidade \\ internacional no seu conjunto, não devem ficar impunes e que a sua repressão \\ deve ser efetivamente assegurada através de medidas em nível nacional e do \\ reforço da cooperação internacional, \\ Decididos a por fim à impunidade dos autores desses crimes e a contribuir \\ assim para a prevenção de tais crimes, (...)”.
}

O legislador do Estatuto de Roma parece que previa a situação em Uganda e na República Centro Africana ao colocar essas palavras. Como não associar os seqüestros e utilização de crianças como soldados ou escravas sexuais à frase "milhões de crianças, homens e mulheres têm sido vítimas de atrocidades inimagináveis que chocam (...)"?. Ou então o fato de Joseph Kony e os líderes do LRA estarem agindo há quase duas décadas cometendo tais crimes com "Decididos a por fim à impunidade dos autores desses crimes e a contribuir assim para a prevenção de tais crimes, (...)".

Seguindo o princípio da complementariedade, pode-se afirmar que o pedido dos presidentes de Uganda e da República Centro Africana ao TPI para investigar os crimes cometidos é uma confissão da incapacidade dos países de julgar tal conflito e da necessidade de apoio internacional através "adoção de medidas em nível nacional e do reforço da cooperação internacional".

\section{Do crime de genocídio:}

O artigo 6 do Estatuto de Roma define que "... entende-se por genocídio qualquer um dos atos que a seguir se enumeram, praticado com intenção de destruir, no todo ou em parte, um grupo nacional, étnico, racial ou religioso, enquanto tal: (a) homicídio de membros do grupo; (b) ofensas graves 
à integridade física ou mental de membros do grupo; (c) sujeição intencional do grupo a condições de vida com vista a provocar a sua destruição física, total ou parcial; (d) imposição de medidas destinadas a impedir nascimentos no seio do grupo; (e) transferência, à força, de crianças de um grupo para outro."

Ora, ao se analisar a realidade fática do conflito, vê-se que pelo menos os itens a, b, e estão presentes nas práticas do LRA. Entretanto, há que se verificar a questão intencionalidade de se destruir, em todo ou em parte, o grupo Acholli. A princípio, poderia se dizer que como os ataques são direcionados a uma região e etnia específica, houvesse crime de genocídio. Entretanto, ao se analisar mais profundamente, vê-se que o objetivo do LRA é mais pragmático: a busca do poder e, portanto, lança mão de práticas atrozes. $\mathrm{Na}$ opnião deste autor, não há que se falar em crime de genocídio. Essa afirmação depreende do fato de que não há crime nem pena sem lei anterior que o defina e que o fato deve enquadrar-se exatamente no tipo penal para que ele tenha efeito. Compare-se o que ocorreu com a definição do tipo penal genocídio. Apesar dos atos terem sido cometidos contra uma população específica, não houve o fator subjetivo, o dolo ou intenção deliberada de se exterminar o povo Acholli. Os atos praticados têm a intenção clara de intimidar a população local e forçá-la apoiar o LRA.

No caso da República Centro Africana, está claro que não há crime de genocídio por tratar-se de conflito essencialmente político.

Dos crimes contra a humanidade

No artigo 7 do Estatuto, define-se como "... ataque, generalizado ou sistemático, contra qualquer população civil, havendo conhecimento desse ataque (a) homicídio; (b) extermínio (c) escravidão (d) deportação ou transferência forçada de uma população (...) (e) prisão (f) tortura (g) agressão sexual (h) perseguição (i) desaparecimento forçado de pessoas (j) crime de apartheid $(k)$ outros atos desumanos".

Pode-se citar que ocorreram nos países os itens a, c, d, f, g, i. k. Verifica-se que nesse caso o tipo penal foi completamente cometido. Houve crime contra a Humanidade em ambos os conflitos. 
Dos crimes de guerra

Há relatos de que tenham sido cometidos crimes de guerra especialmente pelas tropas governamentais em ambos os países. Conforme descrito anteriormente, tem-se notícia de que vários dos crimes descritos no artigo 8 do Estatuto de Roma tenham sido cometidos pelo exército, como homicídio doloso, tortura e utilização de crianças como soldados (artigo 8º, XXVI)

\section{Da admissibilidade}

Constata-se que no caso em questão não se verifica nenhuma das hipóteses de exclusão da admissibilidade constantes do parágrafo $1^{\circ}$ do artigo 17 do Estatuto pois não foi e não está sendo julgado pelos países analisados. $\mathrm{O}$ conflito tem evidente gravidade. Devido à extensão e tempo de duração do conflito, fica clara a incapacidade da execução da justiça pelo próprio Estado. Outro fato questionável é a provável parcialidade de um Tribunal Nacional devido ao histórico de oposição política entre o povo Acholli e o governo atual. Na República Centro Africana, por ser um conflito essencialmente político, essa preocupação é ainda mais importante.

Da execução dos procedimentos processuais e penais

Fato relevante é que boa parte dos integrantes do LRA não podem ser julgados pelo TPI por não terem 18 anos de idade na data que cometeram 0 crime, conforme artigo 26 do Estatuto de Roma.

Outra dificuldade observada é a de se prender a pessoa, conforme artigo 59 do Estatuto de Roma, especialmente se essa for membro do governo, face a possibilidade de insubordinação do Estado-parte. Como o acusado tem que estar presente ao julgamento (artigo 63), com certeza o Estado não está preparado para prender os líderes do LRA. Basta observar que vêm tentando isso há duas décadas. Urge a necessidade de apoio internacional, especialmente da colaboração dos Estados vizinhos como Sudão e Congo. $O$ cumprimento das obrigações contidas no artigo 93 do Estatuto trata-se de um 
desafio à possibilidade fática de sucesso de uma ação do Tribunal Penal Internacional. Os Estado africanos não têm condições políticas e materiais de execução dos procedimentos descritos no referido artigo. É imperativo o apoio material da comunidade internacional para que as ações tenham êxito.

Revista Brasileira de Direito Internacional, Curitiba, v.1, n.1, jan./jun.2005 


\section{CONCLUSÃO}

A primeira questão que se coloca, ao concluir este artigo, é até que ponto a ação do Tribunal Penal Internacional não acabará sendo um instrumento de legitimação dos atos criminosos cometidos pelo poder instituído. Tanto em Uganda, mas em especial na República Centro Africana, o conflito é eminentemente político. Punindo apenas os grupos rebeldes, a Corte Criminal Internacional estaria de certa forma justificando as ações dos governos. Isso poderia ser entendido como uma aceitação da ação dos Estados ditatoriais, já que seus membros não foram punidos. É claro que o TPI necessita do apoio local para a execução de seus objetivos. Entretanto, esse apoio não pode influenciar na imparcialidade da Corte. O limite é muito tênue e é um desafio que está lançado para atuação de seus membros.

Outro ponto que foi discutido nessas páginas é a constatação de que não se pode encarar a justiça como uma ameaça a paz. Empiricamente, as seguidas concessões de anistia, que foram concedidas pelo governo de Uganda em 1995 e 1999, têm-se revelado inadequadas para conter o conflito. É claro que é necessário levar em consideração o risco de vida iminente da população civil envolvida e evitar a hiprocrisia de quem está longe das conseqüências materiais da guerra. Faz-se mister a atuação estruturada da comunidade internacional, garantindo a proteção da população civil até o total desmantelamento do grupo armado. Pensar em conceder perdão aos criminosos com medo das represálias seria um incentivo à continuação de suas atividades. É necessário que a população sinta segurança ou melhor, esperança. É isso o que realmente importa para uma solução real e duradoura para a região.

Revista Brasileira de Direito Internacional, Curitiba, v.1, n.1, jan./jun.2005 


\section{REFERÊNCIAS}

ALL AFRICA. No Fundamental Change for Northern Uganda (AllAfrica.com, 0909-2005) Disponível em HTTP http://allafrica.com/stories/200509090638.html Acesso às 23:45h do dia 15.set.05

BBC NEWS. Uganda conflict 'worse than Iraq' (BBC News, 10-11-2003) Disponível em HTTP http://news.bbc.co.uk/2/hi/africa/3256929.stm Acesso às 00:20h do dia 07.set.05 JESUS, Damásio de. Direito Penal - Parte Geral. São Paulo: Saraiva, 1998.

MONUC NEWS. UN criminal court to target Uganda rebels, DR Congo militia AFP. (Monuc News, 08-02-2005) Disponível em HTTP http://www.monuc.org/news.aspx?hewsID=5480 Acesso às 06:25h do dia 08.set.05

\section{IMAGENS}

Localização de Uganda

Fonte:

http://upload. wikimedia.org/wikipedia/commons/e/ef/LocationUganda.png

Região habitada pelo povo Acholi, que é vítima da ação do LRA Fonte:

http://upload.wikimedia.org/wikipedia/en/6/6a/Acholiland\%2C_Uganda.png

Localização da República Centro Africana

Fonte: http://en.wikipedia.org/wiki/Central African Republic\#Politics

Revista Brasileira de Direito Internacional, Curitiba, v.1, n.1, jan./jun.2005 